Sol, M.E., Bloemen, M.A.T., Verschuren, O., Rushton, P.W., Visser-Meily, J.M.A., Groot, J.F. de. Wheelchair Mobility Confidence Scale for Dutch youth using a manual wheelchair. Disability and Rehabilitation: Assistive Technology: 2019, 15(6), p. 684-691

$\begin{array}{lll}\text { Postprint version } & : & 2.0 \\ \text { Journal website } & : & \frac{\text { https://www.tandfonline.com/doi/full/10.1080/17483107.2019.160483 }}{2 \text { ?scroll=top\&needAccess=true }} \\ \text { Pubmed link } & : & \frac{\text { https://www.ncbi.nlm.nih.gov/pubmed/31012747 }}{\text { DOI }} \\ \text { Do.1080/17483107.2019.1604832 }\end{array}$

This is a Nivel certified Post Print, more info at nivel.nl

\title{
Wheelchair Mobility Confidence Scale for Dutch youth using a manual wheelchair
}

\author{
M. E. Sola,b,c, M. A. T. Bloemen, , O. Verschuren , P. W. Rushton, J. M. A. \\ Visser-Meily $y_{b}$ and J. F. de Groota,e
}

A Research Group Lifestyle and Health, HU University of Applied Sciences Utrecht, Utrecht, The Netherlands;

в Brain Center Rudolf Magnus and Center of Excellence for Rehabilitation Medicine, University Medical Center Utrecht and De Hoogstraat Rehabilitation, Utrecht, The Netherlands; c De Hoogstraat Rehabilitation, Special Needs School, Utrecht, The Netherlands; D école de réadaptation, Université de Montréal, Montréal, Canada; E Netherlands Institute for Healthcare Services Research (NIVEL), Utrecht, The Netherlands

\footnotetext{
ABSTRACT

Purpose: The objective of this study was to develop a questionnaire to assess confidence in wheelchair mobility in Dutch youth (WheelConMobility Dutch Youth).

Methods: (1) A forward-backward translation process was used to translate the original WheelConM from English to Dutch. (2) Items related to wheelchair mobility in Dutch youth were selected and adapted based on focus groups with youth, parents and health care professionals to create the WheelConMobility Dutch Youth. (3) The WheelConMobility Dutch Youth and the Utrecht Pediatric Wheelchair Mobility Skills Test 2.0 (UPWMST 2.0) were administered to 62 participants to evaluate internal consistency and construct validity.

Results: Translation and cultural adaptation led to general adaptations in instructions, sentence structure and response scale. At the item level, 24 items were included with (n $=17$ ) and without $(n=7)$ adaptation, 10 items were deleted and 7 new items were included. The WheelConMobility Dutch Youth had an excellent Cronbach's alpha of 0.924 and a significant correlation $(r=0.44, p<.001)$ with the UPWMST 2.0.

Conclusions: This study resulted in the adaptation of the WheelConM into the WheelConMobility for Dutch youth using a manual wheelchair. Our study suggests there is evidence supporting the internal consistency and construct validity of the WheelConMobility Dutch Youth.

_ IMPLICATIONS FOR REHABILITATION
} 
Sol, M.E., Bloemen, M.A.T., Verschuren, O., Rushton, P.W., Visser-Meily, J.M.A., Groot, J.F. de. Wheelchair Mobility Confidence Scale for Dutch youth using a manual wheelchair. Disability and Rehabilitation: Assistive Technology: 2019, 15(6), p. 684-691

_ The WheelConMobility Dutch Youth is a newly developed tool for assessing confidence in wheelchair mobility in Dutch youth using a manual wheelchair.

_ It is important to assess performance and confidence in wheelchair mobility in paediatric rehabilitation.

\section{Introduction}

When looking at physical activity behaviour, studies have shown that youth (children and adolescents) using a manual wheelchair is more sedentary and less physically active than ablebodied peers [1-3] and peers with a disability who are ambulatory [4]. In a study of Dutch youth using a manual wheelchair, Bloemen et al.

[5] reported that youth with spina bifida was approximately 72 min physically active on a school day compared to 175 min of physical activity time for typically developing peers.

To improve physical activity behaviour in youth with a disability, recent reviews concluded that interventions should not only focus on body functions and impairments, but also take personal factors, such as confidence and environmental factors, such as the importance of a good assistive device, into account $[5,6]$.

Similarly, two qualitative studies $[7,8]$ have described that confidence and wheelchair mobility skills are important factors in facilitating participation in physical activity. These results are in line with Bandura's social cognitive theory, where confidence is strongly related to motivation and an important factor for changes in behaviour [9]. Therefore, to improve physical activity in youth using a manual wheelchair, confidencespecific targeted interventions and measurement instruments need to be developed and implemented.

To the best of our knowledge, there is currently no questionnaire available to assess confidence in wheelchair mobility in youth.

However, to assess confidence in wheelchair use in adults, there are two questionnaires available: the Wheelchair Use Confidence Scale for people who use a manual wheelchair (WheelConM) [10] and the SelfEfficacy in Wheeled Mobility (SEWM) [11]. In the literature, the WheelConM [10,12-19] has been reported more extensively than the SEWM [11]. Measurement properties of the WheelConM have been studied thoroughly and evidence has shown that the WheelConM is a valid and reliable questionnaire to measure confidence in wheelchair use in adults [13]. The original WheelConM is a selfreport 65item questionnaire on a 101point response scale for Englishspeaking adults using a manual wheelchair. It measures several areas of confidence in wheelchair use including "negotiating the environment," "activities performed in the wheelchair," "knowledge and problem solving," "advocacy," "managing social situations" and "managing emotions" [12]. Studies using the WheelConM have demonstrated an association between lower confidence in wheelchair use and lower levels of participation frequency and life space mobility $[10,19]$. It stands to reason that there would be similar associations in the paediatric population. The aim of this study was to develop a measure to assess confidence in wheelchair mobility among Dutch youth, where confidence in wheelchair mobility is defined as the belief individuals have in their ability to use their wheelchair in a variety of physically challenging situations. Specific study objectives were (1) to translate the original WheelConM into the WheelConM Dutch, (2) to select items specific to confidence in wheelchair mobility and to culturally adapt these items for Dutch youth using a manual wheelchair (WheelConMobility Dutch Youth) and (3) to evaluate the internal consistency and construct validity of the WheelConMobility Dutch Youth. 
Sol, M.E., Bloemen, M.A.T., Verschuren, O., Rushton, P.W., Visser-Meily, J.M.A., Groot, J.F. de. Wheelchair Mobility Confidence Scale for Dutch youth using a manual wheelchair. Disability and Rehabilitation: Assistive Technology: 2019, 15(6), p. 684-691

\section{Methods}

\section{Design}

The WheelConMobility Dutch Youth was developed using a threephase mixedmethods design. Phase 1: Translation consisted of a forward-backward translation process. Phase 2: Item Selection and Cultural Adaptation was accomplished using focus groups. Phase 3: Baseline results of a larger intervention study were used for the Evaluation of Internal Consistency and Construct Validity. The Medical Ethics Committee of the University Medical Center Utrecht, the Netherlands, approved the study procedures (15-136). All participants provided informed consent.

\section{Phase 1: translation}

For the translation of the original WheelConM from English to Dutch we used the Translation and Cultural Adaptation of Patient Reported Outcomes Measures - Principles of Good Practice guidelines [20], the same method used by Rushton et al. [15] who translated the original WheelConM into French. This method consists of nine steps.

In step one, the translation team was assembled which consisted of: three members (MS, OV and JdG) whose first language is Dutch and second language is English, who live in the Netherlands and who have a background in the subject area of paediatric manual wheelchair users; one member (TS) who is a native English speaker with Dutch as his second language who has lived in the Netherlands for 17 years; and one Canadian member (PWR) whose first language is English, with extensive expertise in wheelchair confidence being the developer of the original WheelConM. The second step involved independent forward translations from English to Dutch by two team members (MS and OV). For the third step, both forward translations were compared and discrepancies were resolved through consensus by the Dutch members of the team. The fourth step was a parallel back translation from Dutch into English by two team members (JdG and TS). In step five, the back translation was compared to the original version by the Canadian researcher and discrepancies were resolved through consensus by the research team. Steps six to eight, the harmonization, cognitive debriefing and review of cognitive debriefing were not included as part of this study. Step nine, proofreading of the Dutch translation of the WheelConM was conducted by the Dutch team members in preparation for Phase 2.

Phase 2: item selection and cultural adaptation

\section{Participants}

Purposive sampling was used to recruit health care professionals/ educators, children who use a manual wheelchair (aged 6-12) and their parents, adolescents who use a manual wheelchair (aged 13-18) and their parents. Health care professionals/educators were eligible to participate if they were an OT, PT, physical education teacher, paediatric psychologist or an independent wheelchair mobility skills trainer (educator) with over 3 years of experience working with youth who use a wheelchair. They were recruited from two rehabilitation centres (De Hoogstraat and Merem) in the Netherlands and from a company (KJ projects) that teaches wheelchair mobility skills trainings in the Netherlands. Youth were eligible to participate if either their parents or their health care professional thought they were capable of speaking about confidence in wheelchair mobility, used their wheelchair for more than 1 year and for more than 4 hours on a daily basis. They were recruited through local physiotherapists at the same two rehabilitation centres from where the health care professionals were recruited or through the Let's Ride database, a database of youth using a manual wheelchair who previously participated in research of the Research Group of Lifestyle and Health and consented to being contacted again. Parents were recruited through their corresponding participating child. The ability to speak in Dutch and to participate in a focus group were eligibility criterion for all participants. 
Sol, M.E., Bloemen, M.A.T., Verschuren, O., Rushton, P.W., Visser-Meily, J.M.A., Groot, J.F. de. Wheelchair Mobility Confidence Scale for Dutch youth using a manual wheelchair. Disability and Rehabilitation: Assistive Technology: 2019, 15(6), p. 684-691

\section{Procedure}

Five focus groups were held with the health care professionals/ educators $(n=1)$, children $(n=1)$, adolescents $(n=1)$ and parents $(n=2)$. Each focus group was conducted by an experienced moderator and assistant moderator using a stakeholderspecific focus group guide. The aim of the session with health care professionals/educators was to discuss (1) children's ability to understand the term "confidence," (2) identify general adaptations of the WheelConM Dutch translation for Dutch youth, (3) discuss on item level selection of items related to wheelchair mobility and (4) determine relevancy of selected items for Dutch youth.

Prior to this focus group, participants received a demographic questionnaire, a brief overview of the study rationale and the translated WheelConM. Participants were asked to review in advance the translated WheelConM and to prepare to discuss aims 3 and 4 (described above). The focus groups with children, adolescents and parents were conducted with the aims of (1) discussing children's ability to understand the term "confidence" and (2) to identify additional relevant items for measuring confidence with wheelchair mobility, which are not yet included in the WheelConM Dutch translation. Prior to these focus groups, the parents received a demographic questionnaire and a brief overview of the study rationale. Parents and youth did not receive the translated WheelConM to assure an unbiased opinion about relevant topics on confidence in wheelchair mobility. All focus groups were audio recorded and transcribed verbatim.

\section{Data analysis}

Two independent researchers analyzed the transcripts of the focus groups using a content framework approach [21]. Data from the focus group with health care professionals/educators were coded according to the four aims of the session. Segments of the focus groups with youth and their parents were coded as "definition of confidence," "existing items from the WheelConM" or as "new items." Differences in coding were resolved through discussion between three Dutch team members (MS, OV and JdG) until consensus was reached. After analysis of the focus group with health care professionals/educators and the analysis of the combined four focus groups with youth and their parents, both results were combined to decide if an item was relevant for assessing wheelchair mobility in Dutch youth. When an item was deemed less relevant by health care professionals/educators and not mentioned by youth or their parents it was considered to be irrelevant for Dutch youth. The results were discussed in the research group, which led to the adaptation of the WheelConM into the WheelConMobility Dutch Youth. The WheelConMobility Dutch Youth was digitalized in an online survey programme for ease of administration using a tablet in phase 3 of this study.

\section{Phase 3 internal consistency and construct validity}

\section{Participants}

This phase of the study was part of an ongoing larger intervention study evaluating the effectiveness of a wheelchair mobility skills training programme for youth attending rehabilitation centres and schools for special education in the Netherlands (trialregister.nl, registration number NTR5791). A convenience sample of participants was recruited by local physiotherapists and occupational therapists in the participating rehabilitation centres/schools for special education $(n=6)$. To be included in this study, participants needed to be: between 7 and 18 years of age, (bimanual) wheelchair user on a daily basis, able to understand the spoken Dutch language and able to understand simple instructions. Participants were excluded if they had undergone a medical intervention during the previous 6 months that could have affected the intervention study outcomes (e.g., botoxinjections). 
Sol, M.E., Bloemen, M.A.T., Verschuren, O., Rushton, P.W., Visser-Meily, J.M.A., Groot, J.F. de. Wheelchair Mobility Confidence Scale for Dutch youth using a manual wheelchair. Disability and Rehabilitation: Assistive Technology: 2019, 15(6), p. 684-691

\section{Outcome measures}

The resulting WheelConMobility Dutch Youth developed in phase 2 (Figure 1 and Appendix) was used in phase 3 for assessment of internal consistency and construct validity.

The Utrecht Pediatric Wheelchair Mobility Skills Test 2.0 (UPWMST 2.0) $[22,23]$ is a recently developed and validated objective, performancebased measure of wheelchair mobility skills for children and adolescents using a manual wheelchair. It consists of 15 items, such as propulsion forward/backward, turning, holding a wheelie and ascending and descending slopes and platforms. The total score may range from 0 to 51, with a higher score representing more advanced wheelchair mobility skills [23]. We hypothesized that the WheelConMobility Dutch Youth would have a positive lowmoderate correlation ( $r=0.3-0.7)$ with the UPWMST 2.0, given that wheelchair mobility skills and wheelchair confidence in the adult population have demonstrated a positive, moderate correlation [19].

\section{Procedure}

All measures were administered at baseline. The WheelCon Mobility Dutch Youth was administered with support from a researcher or research assistant when necessary. The UPWMST 2.0 was administered by a local PT or OT, who had received a $4 \mathrm{~h}$ training (theory and practice) on how to administer this outcome measure.

\section{[Figure 1].}

\section{Data analyses}

Cronbach's alpha was calculated as a parameter of internal consistency.

A Cronbach's alpha of $0.5-0.6$ was considered as poor, $0.6-0.7$ as questionable, $0.7-0.8$ as acceptable, $0.8-0.9$ as good and $>0.9$ as excellent [24].

For construct validity, we visually checked if the data were normally distributed using histograms, QQplots and assessed normality using the KolmogorovSmirnov Test. Consecutively, we analyzed the linearity of the data graphically by scatterplots.

Depending on the normality of the data, Pearson correlation coefficients or Spearman correlation coefficients were used to calculate the correlation. Low correlation was defined as $r=0.3-0.5$, moderate correlation as $r=0.5-0.7$, high correlation as $r=0.7-0.9$ and excellent correlation as $r=0.9-$ 1.0 [24]. Finally, we assessed if there was a change in correlation between the WheelConMobility Dutch Youth and the UPWMST 2.0 when corrected for age.

\section{Results.}

\section{Phase 1: translation.}

The translation of the WheelConM from English to Dutch revealed some important topics. As the research team felt the concept of confidence is difficult to understand, especially for children, they decided it was an important topic that had to be discussed during the focus groups. In addition, adjustment to Dutch standard building codes of items regarding ramps, slopes or curbs were considered. Because the degrees and heights of the ramps, slopes and curbs are similar in Canada and the Netherlands no adjustments were necessary.

Phase 2: item selection and cultural adaptation

Seven participants took part in the health care professional/educator focus group. Participant characteristics are presented in Table 1. In terms of aim (1), minimal age to understand concept of confidence, after discussion consensus was reached that at 8 years of age a child with normal cognitive function would be able to understand the concept of confidence and independently complete the questionnaire. This decision was based on the expertopinion of the paediatric psychologist. 
Sol, M.E., Bloemen, M.A.T., Verschuren, O., Rushton, P.W., Visser-Meily, J.M.A., Groot, J.F. de. Wheelchair Mobility Confidence Scale for Dutch youth using a manual wheelchair. Disability and Rehabilitation: Assistive Technology: 2019, 15(6), p. 684-691

Furthermore, the health care professionals suggested that "confidence" should be clearly defined at the beginning of the questionnaire in simple and concrete language. In terms of aim (2), general adaptations, participants suggested to modify the original 101point response scale, as this was considered too complicated for younger participants.

Consensus was reached about using a 5point scale ranging from 1 (no confidence) to 5 (very high confidence). It was proposed that the scale be visually supported by five circles in ascending size, from small (no confidence) to big (very high confidence).

Furthermore, the appropriateness of the sentence structure for youth was discussed. This discussion led to adjustment of the stem to make it grammatically correct in Dutch and to include the words "independently" and "safely" to remind the participants the items are about an independent performance. To visually support the questions and to make it easier for youth to understand and answer the questions, participants advised to include photos. As a result, the research team added photos to 15 items (Appendix).

In terms of aim (3), relevance to wheelchair mobility, only the items in the domain "negotiating the environment $(n=34)$ " were deemed relevant for assessing confidence in wheelchair mobility among Dutch youth. The other items $(n=31)$ from the WheelConM are related to other aspects of wheelchair use. In terms of aim (4), relevance for Dutch youth, five items were deemed not relevant in Dutch weather conditions. Twentynine of the items in the domain "negotiating the environment" were considered relevant for youth. However, when discussing the importance of making the questionnaire as short as possible for youth, some items were deemed less relevant $(n=5)$ and could possibly be removed from the questionnaire.

Demographic characteristics of the participants in the four focus groups with children $(n=5)$, adolescents $(n=3)$ and parents $(n=3$ and $n=6)$ are presented in Table 1. Data from these focus group transcripts were analyzed according to children's ability to understand the term confidence (aim 1) and items to measure confidence with wheelchair mobility (aim 2). In terms of aim (1), participants gave different descriptions and suggestions on how to explain confidence to a child. For aim (2), participants in these focus groups identified 22 items that were already present in the WheelConMobility Dutch Youth and 7 new items, including cross a busy street without a crosswalk or traffic light, cross over a road with a 5_ incline, move wheelchair down 3 steps, move wheelchair up and down an escalator, propelling the wheelchair without antitipping wheels and performing a wheelie.

These results were combined with the outcome of the focus group with health care professionals/educators. All items that were deemed less relevant $(n=10)$ by health care professionals/ educators were not mentioned in the focus groups with youth and their parents. Therefore, these items were deleted from the questionnaire. This process led to a total of 31 items in the WheelConMobility Dutch Youth, with a minimal score of 31 and a maximal score of 155.

\section{Phase 3: internal consistency and construct validity}

The characteristics of the 62 participants included in this phase of the study are presented in Table 2. Four participants were unable to complete the questionnaire due to cognitive disabilities and thus their data were removed from the analyses. The remaining 58 participants, with a mean age of 13 years, completed the WheelConMobility Dutch Youth with a mean score of 109 (SD 22, range 55-154) in 15-25 min. The WheelConMobility Dutch Youth and UPWMST 2.0 (mean 31.4, standard deviation 10.1) data were normally distributed.

[table 2].

Cronbach's alpha of the 31item WheelConMobility Dutch Youth was excellent (0.924). Analyzing "Cronbach's alpha if item deleted" showed that no items needed to be deleted. 
Sol, M.E., Bloemen, M.A.T., Verschuren, O., Rushton, P.W., Visser-Meily, J.M.A., Groot, J.F. de. Wheelchair Mobility Confidence Scale for Dutch youth using a manual wheelchair. Disability and Rehabilitation: Assistive Technology: 2019, 15(6), p. 684-691

Figure 2 shows the scatterplot of the correlation between the WheelConMobility Dutch Youth and the UPWMST 2.0 with the confidence interval. We found a positive correlation between the WheelConMobility Dutch Youth and the UPWMST $2.0(r=0.44, p<.001)$. No changes in significance of correlations were found when corrected for age $(r=0.43, p<.001)$.

\section{Discussion}

To the best of our knowledge, this is the first study reporting on an outcome measure to assess confidence in wheelchair mobility in youth using a manual wheelchair.

An important consideration in phase 2 of this study was the ability of youth to understand the concept of confidence and answer questions about their own confidence. Our finding of a minimum age of 8 years is in line with evidence from the literature, where a child with normal cognitive abilities should be able to understand the concept of reflection and comparing themselves to peers at the age of 7-8 years old $[25,26]$. Several adaptations were made in the WheelConMobility Dutch Youth to increase the understanding of the question (photos) and answer options (5point response scale) for youth. These adaptations are similar to the use of examples and 5 point Likert Scale in a Quality of Life Questionnaire for people with an intellectual disability [27]. Given these adaptations for youth, one should keep in mind that decreased cognitive abilities may affect the ability to complete the WheelConMobility Dutch Youth. Our advice is to accompany a child when administering the WheelConMobility Dutch Youth, to allow a child to ask clarification if needed. A similar method is used in the administration of the Self Perception Profile for Children in young children at kindergarten level [28].

However, even with adult support four children (aged 10-12 years old) with severe learning problems out of the 17 participants with mild to severe learning problems in phase 3 of this study were unable to complete the WheelConMobility Dutch Youth. Future research, by using a thinkaloud process, may give more insight into how children, and specifically children with decreased cognitive abilities understand and answer items regarding confidence.

This may lead to further refinement of the questionnaire or development of proxy reports by parents. [table 2] [figure 2] Another aim of this study was to select items related to wheelchair mobility. The selection of these items based on the qualitative results of the focus groups are in line with the shortform list of items selected through a Rasch analyses of the WheelConM [10], contributing to the content validity of this questionnaire.

Interestingly, most of the wheelchair mobility items from the existing questionnaire for adults were deemed relevant for youth.

These results are similar to the development of the UPWMST, where most of the wheelchair mobility skills for adults were also relevant to assess in youth and show that youth encounter similar barriers when negotiating their wheelchair [22]. There are, however, some important basic additions specifically for youth in this questionnaire, such as propelling the wheelchair without antitippers, and performing a wheelie, which is also in line with the development of the UPWMST 2.0, where more basic skills were included in a wheelchair mobility skills test for youth [22].

Surprisingly, there was also the addition of more advanced wheelchair mobilityrelated items, such as going up and down an escalator.

It was not possible to distinguish from this data, if the use of an escalator with a wheelchair might be more relevant for the Dutch situations or for youth specifically. Further research towards validating the WheelConM in the Dutch adult population could give more insight.

Furthermore, this study shows similar evidence towards internal consistency (Cronbach's alpha 0.92) of the WheelCon Mobility Dutch Youth as the original WheelConM and translated versions of the WheelconM (Cronbach's alpha 0.92-0.98) [12,14,15]. Deletion of items did not lead to a higher Cronbach's alpha and this finding supports the inclusion of all current items. 
Sol, M.E., Bloemen, M.A.T., Verschuren, O., Rushton, P.W., Visser-Meily, J.M.A., Groot, J.F. de. Wheelchair Mobility Confidence Scale for Dutch youth using a manual wheelchair. Disability and Rehabilitation: Assistive Technology: 2019, 15(6), p. 684-691

Nevertheless, the current time to complete the questionnaire is 15-25 min and future research using Rasch analyses in a larger sample size could lead to further adaptation of the WheelCon Mobility Dutch Youth into a short form as has been done in the adult English [10] and Italian version [14].

For evidence regarding construct validity, we confirmed our hypotheses regarding a significant low to moderate positive correlation ( $r s=0.44$ ) between the WheelConMobility Dutch Youth and the UPWMST 2.0 [23]. The strength of this correlation was lower than the correlation reported in adult manual wheelchair users $(r=0.52)$ [19]. A lower correlation in youth could possibly be explained by a larger overestimation of their own capabilities compared to adults [26]. When looking at the distribution of scores in this study, there were four participants who had a high confidence in performing wheelchair mobility skills, but a low capacity of performing skills. Interestingly, these conflicting scores were also found in adult wheelchair users [19]. It is therefore important to asses both the confidence in wheelchair mobility and the wheelchair mobility skill level in youth in clinical practice.

\section{Strengths and limitations}

Collaborating with the original developer of the WheelConM and the use of the translation and cultural adaptation of patient reported outcomes measures [20] during translation from English to Dutch were strengths in our research. Furthermore, we used qualitative research with a variety of stakeholders, including health care professionals, parents and youth in order to decide which adjustments should be made for the youth version. In addition, a sample size of 58 youth for quantitative analyses was larger than the sample size used in the Italian [14] and French translation [15]. The evidence for internal consistency and construct validity was proven in a heterogeneous sample, with different diagnoses, ages and learning difficulties. The heterogeneity of this sample is a good representation of the Dutch youth who use a manual wheelchair in daily life, supporting the use of this outcome measure in clinical practice. The design of the focus groups with children, adolescents and parent ascertained an open mind, but this also made it impossible to check if all items together reflect the whole topic of confidence in wheelchair mobility in youth. Further research into the structure of the WheelCon Mobility Dutch Youth using a factor analyses is necessary to confirm if these original, adapted and new items belong to the same domain of confidence in wheelchair mobility in youth. Due to our research design of the larger ongoing study, we were not able to analyze the test-retest reliability and therefore we were not able to look at agreement and measurement error. Although the original and translated versions do show good test-retest reliability, it would still be recommended to study test-retest reliability of this adapted version of the WheelConMobility Dutch Youth [14,15].

\section{Conclusion}

This study resulted in the adaptation of the WheelConM into the WheelConMobility for Dutch Youth using a manual wheelchair. It shows positive evidence towards internal consistency and construct validity of the WheelConMobility Dutch Youth. Future studies should lead to further refinement of the WheelConMobility Dutch Youth, assess test-retest agreement and measurement error. In clinical practice, it is important to assess confidence in wheelchair mobility and the capacity of performing a wheelchair mobility skill to choose the most appropriate treatment method.

\section{Acknowledgements}

This study is part of the Fit For the Future collaboration; H. Wittink, A. Dallmeijer, R van den BergEmons. We would like to thank all participating children, their parents and health care professionals for volunteering their time and sharing their experiences with us. We would like to thank Tim Schilling for his help with the translations. We would like to thank all the participating students who have enthusiastically contributed to the data collection and analysis in the Let's Ride study. We 
Sol, M.E., Bloemen, M.A.T., Verschuren, O., Rushton, P.W., Visser-Meily, J.M.A., Groot, J.F. de. Wheelchair Mobility Confidence Scale for Dutch youth using a manual wheelchair. Disability and Rehabilitation: Assistive Technology: 2019, 15(6), p. 684-691

are especially grateful to the BOSK patient organization and KJprojects for sharing their expertise and involvement in the Wheelchair Mobility Skills Training program.

Disclosure statement The authors report no conflict of interest.

Funding This work was supported by the SIARAAK under grant [PRO4-03] and the Dutch Foundation for Disabled Children [20150131].

\section{References}

[1] Bloemen M, vd BergEmons R, Tuijt M, et al. Physical activity in wheelchairusing youth with spina bifida: an observational study. Accepted in J Neuroeng Rehabil. 2019;16(1):9.

[2] Buffart LM, Westendorp T, van den BergEmons RJ, et al. Perceived barriers to and facilitators of physical activity in young adults with childhoodonset physical disabilities. J Rehabil Med.

2009;41:881-885.

[3] Nooijen CFJ, Post MWM, Spooren AL, et al. Exercise selfefficacy and the relation with physical behavior and physical capacity in wheelchairdependent persons with subacute spinal cord injury. $J$ Neuroeng Rehab. 2015;12:103.

[4] van den BergEmons RJ, Bussmann JB, Stam HJ. Accelerometrybased activity spectrum in persons with chronic physical conditions. Arch Phys Med Rehabil. 2010; 91:1856-1861.

[5] Bloemen M, Van Wely L, Mollema J, et al. Evidence for increasing physical activity in children with physical disabilities: a systematic review. Dev Med Child Neurol. 2017;59: 1004-1010.

[6] Shields N, Synnot AJ, Barr M. Perceived barriers and facilitators to physical activity for children with disability: a systematic review. Br J Sports Med. 2012;46:989-997.

[7] Bloemen MA, Verschuren O, van Mechelen C, et al. Personal and environmental factors to consider when aiming to improve participation in physical activity in children with Spina Bifida: a qualitative study. BMC Neurol. 2015;15:11.

[8] Shields N, Synnot A. Perceived barriers and facilitators to participation in physical activity for children with disability: a qualitative study. BMC Pediatr. 2016;16:9.

[9] Bandura A. Selfefficacy: the exercise of control. New York (NY): W. H. Freeman and Company; 1997.

[10] Sakakibara BM, Miller WC, Rushton PW. Rasch analyses of the wheelchair use confidence scale. Arch Phys Med Rehabil. 2015;96:1036-1044.

[11] FliessDouer O, van der WL, Vanlandewijck YC. Development of a new scale for perceived selfefficacy in manual wheeled mobility: a pilot study. J Rehabil Med. 2011;43:602-608.

[12] Rushton PW, Miller WC, Lee Kirby R, et al. Development and content validation of the Wheelchair Use Confidence Scale: a mixedmethods study. Disabil Rehabil Assist Technol. 2011;6:57-66.

[13] Rushton PW, Miller WC, Kirby RL, et al. Measure for the assessment of confidence with manual wheelchair use (WheelConM) version 2.1: reliability and validity. J Rehabil Med.

2013;45:61-67.

[14] Berardi A, De Santis R, Tofani M, et al. The Wheelchair Use Confidence Scale: Italian translation, adaptation, and validation of the short form. Disabil Rehabil Assist Technol. 2017;13:16.

[15] Rushton PW, Routhier F, Miller WC, et al. FrenchCanadian translation of the WheelConM (WheelConMF) and evaluation of its validity evidence using telephone administration. Disabil Rehabil. 2015;37:812-819.

[16] Rushton PW, Smith E, Miller WC, et al. Measuring wheelchair confidence among power wheelchair users: an adaptation of the WheelConM using focus groups and a think aloud process. Disabil Rehabil Assist Technol. 2017;12: 39-46. 
Sol, M.E., Bloemen, M.A.T., Verschuren, O., Rushton, P.W., Visser-Meily, J.M.A., Groot, J.F. de. Wheelchair Mobility Confidence Scale for Dutch youth using a manual wheelchair. Disability and Rehabilitation: Assistive Technology: 2019, 15(6), p. 684-691

[17] Sakakibara BM, Miller WC, Routhier F, et al. Association between selfefficacy and participation in communitydwelling manual wheelchair users aged 50 years or older. Phys Ther. 2014;94:664674.

[18] Sakakibara BM, Miller WC, Eng JJ, et al. Influences of wheelchair related efficacy on lifespace mobility in adults who use a wheelchair and live in the community. Phys Ther. 2014;94:1604-1613. [19] Sakakibara BM, Miller WC. Prevalence of low mobility and selfmanagement selfefficacy in manual wheelchair users and the association with wheelchair skills. Arch Phys Med Rehabil. 2015;96:1360-1363.

[20] Wild D, Grove A, Martin M, et al. ISPOR task force for translation and cultural adaptation: principles of good practice for the translation and cultural adaptation process for patientreported outcomes (PRO) measures: report of the ISPOR Task Force for Translation and Cultural Adaptation. Value Health. 2005;8:94-104.

[21] Gale NK, Heath G, Cameron E, et al. Using the framework method for the analysis of qualitative data in multidisciplinary health research. BMC Med Res Methodol. 2013;13:117. [22] Sol ME, Verschuren O, de Groot L, FitFortheFuture!consortium. Development of a wheelchair mobility skills test for children and adolescents: combining evidence with clinical expertise. BMC Pediatr. 2017;17:51.

[23] Sol M, de Groot J, Zwinkels M, et al. The Utrecht Pediatric Wheelchair Mobility Skills Test: validity, reproducibility and responsiveness in children and adolescents using a manual wheelchair. [Epub ahead of print].

[24] Portney LG, Watkins MP. Foundations of clinical research: application to practice. 3rd ed. Upper Saddle River: Prentice Hall; 2009.

[25] Veerman JW, Straathof MAE, Treffers PDA, et al. Handleiding Competentiebelevingsschaal voor Kinderen (CBSK) (Manual for the Dutch version of the SPPC). Lisse (The Netherlands): Swets \& Zeitlinger; 1997.

[26] Fredricks JA, Eccles JS. Children's competence and value beliefs from childhood through adolescence: growth trajectories in two malesextyped domains. Dev Psychol. 2002; 38:519-533. [27] Smith EM, Sakakibara BM, Miller WC. A review of factors influencing participation in social and community activities for wheelchair users. Disabil Rehabil Assist Technol. 2016; 11:361-374. [28] Noordstar JJ, van der Net J, Jak S, et al. The change in perceived motor competence and motor task values during elementary school: a longitudinal cohort study. $\mathrm{Br} \mathrm{J}$ Dev Psychol. 2016;34:427-446.

Tables and figures 
Sol, M.E., Bloemen, M.A.T., Verschuren, O., Rushton, P.W., Visser-Meily, J.M.A., Groot, J.F. de. Wheelchair Mobility Confidence Scale for Dutch youth using a manual wheelchair. Disability and Rehabilitation: Assistive Technology: 2019, 15(6), p. 684-691

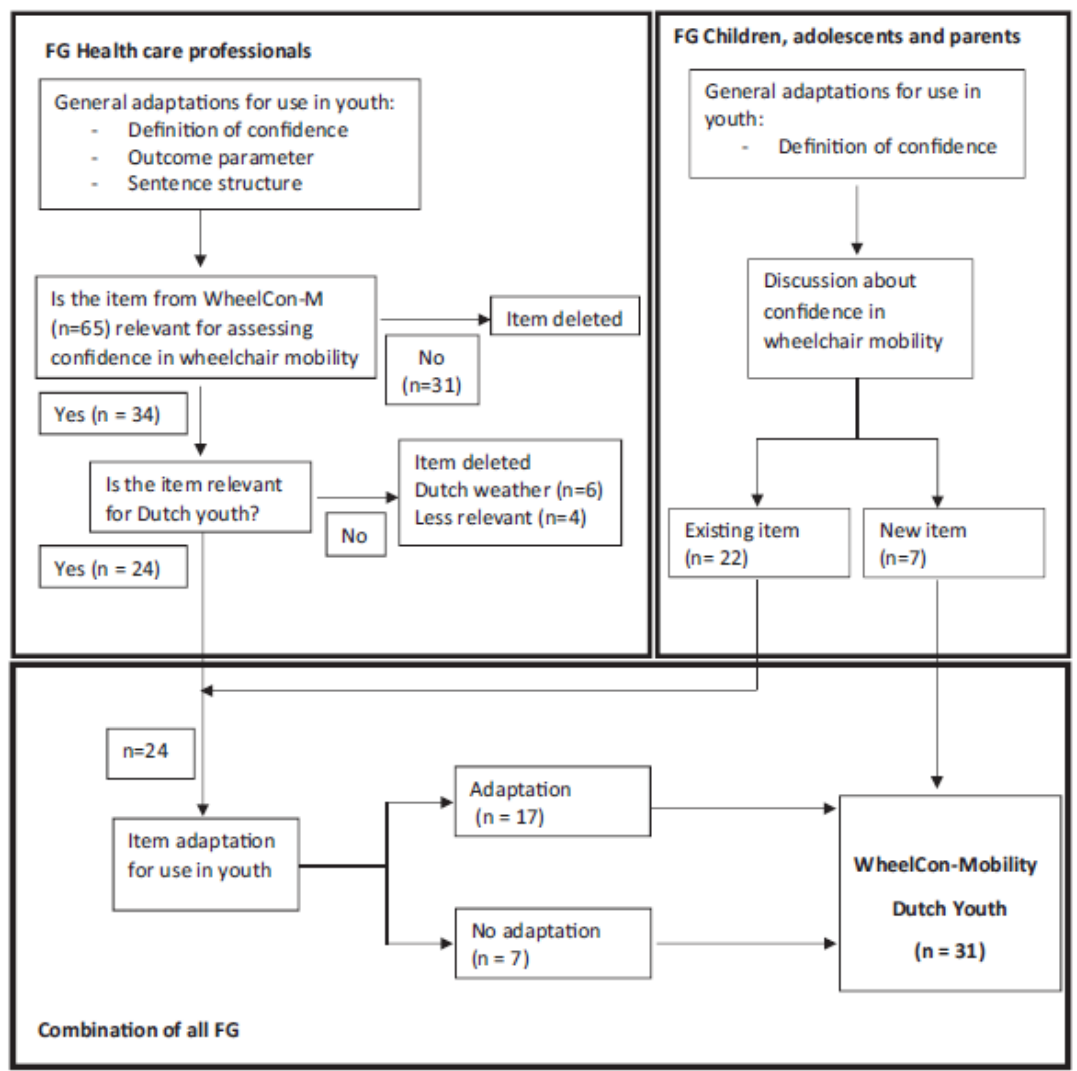

Figure 1. Results of adaptation of WheelCon-M into WheelCon-Mobility Dutch Youth in phase 1. FG: focus group; WheelCon-Mobility Dutch Youth: Wheelchair Mobility Confidence Scale for Dutch youth.

Table 1. Characteristics of participants of focus group in phase 2.

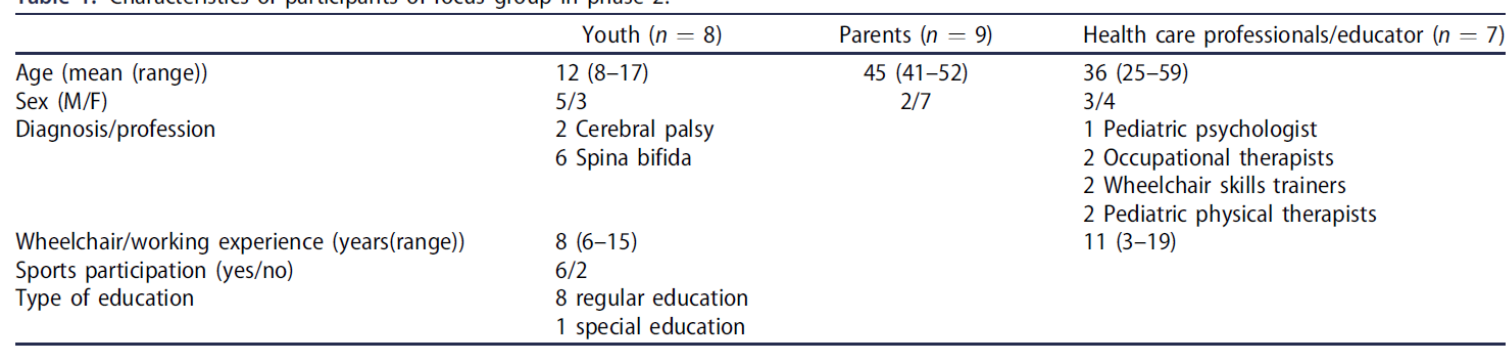

Table 2. Characteristics of participants in phase 3.

\begin{tabular}{ll}
\hline & \multicolumn{1}{c}{ Participants $(n=58)$} \\
\hline Age & 13.0 (SD 3.3, range 7.1-18.8) \\
Sex & 34 boys, 24 girls \\
Diagnosis & 23 Cerebral palsy \\
& 10 Spina bifida \\
& 8 Neuromuscular disease \\
& 15 Other \\
Progressive disorder & 47 no \\
& 11 yes \\
Wheelchair experience (years) & 8.4 (mean 4.0, range 1-15) \\
Level of education & 37 No learning problems \\
& 21 Mild or severe learning problems \\
\hline
\end{tabular}


Sol, M.E., Bloemen, M.A.T., Verschuren, O., Rushton, P.W., Visser-Meily, J.M.A., Groot, J.F. de.

Wheelchair Mobility Confidence Scale for Dutch youth using a manual wheelchair. Disability and Rehabilitation: Assistive Technology: 2019, 15(6), p. 684-691

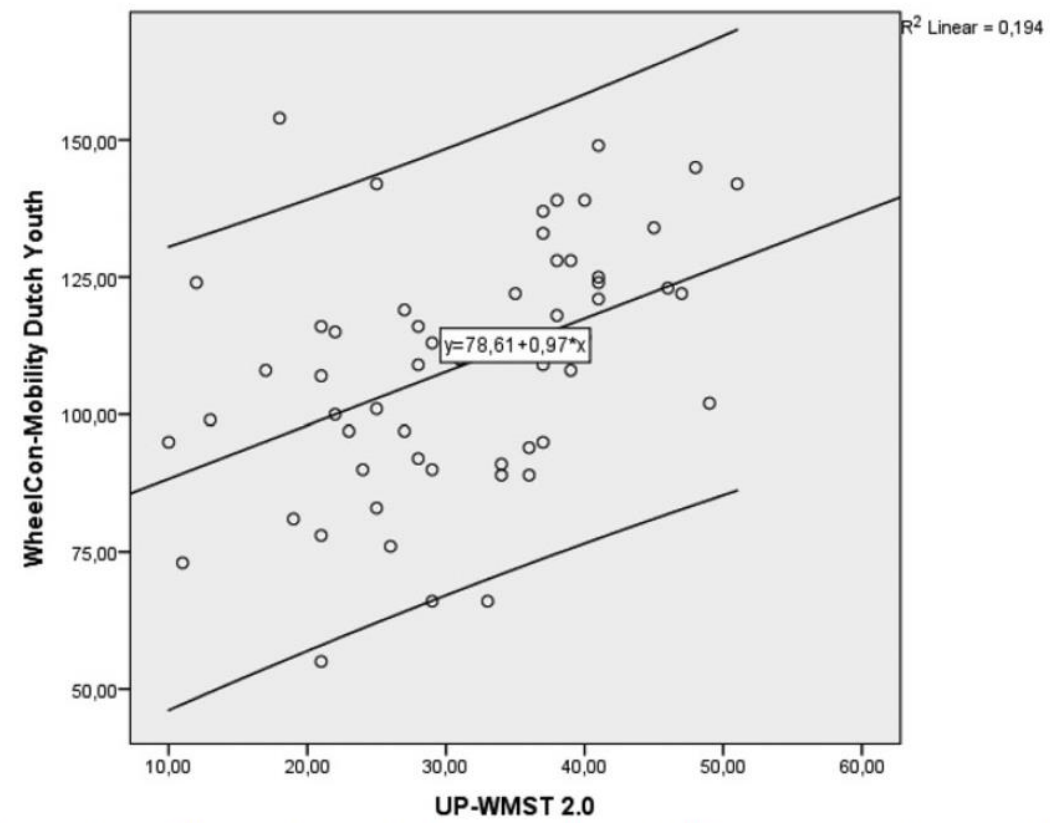

Figure 2. Scatterplot of the Wheelchair Mobility Confidence Scale for Dutch youth (WheelCon-Mobility Dutch Youth) and the Utrecht Pediatric Wheelchair Mobility Skills Test (UP-WMST 2.0) with the confidence interval. 
Sol, M.E., Bloemen, M.A.T., Verschuren, O., Rushton, P.W., Visser-Meily, J.M.A., Groot, J.F. de.

Wheelchair Mobility Confidence Scale for Dutch youth using a manual wheelchair. Disability and Rehabilitation: Assistive Technology: 2019, 15(6), p. 684-691

Appendix. Adaptations of WheelCon-M per item.

\begin{tabular}{|c|c|c|c|}
\hline $\begin{array}{l}\text { Items related to wheelchair mobility from original WheelCon and } \\
\text { new items }\end{array}$ & $\begin{array}{c}\text { FG health care } \\
\text { professionals } \\
\text { relevant (yes/no) }\end{array}$ & $\begin{array}{l}\text { FG dhilden (C) } \\
\text { adolescents (A) } \\
\text { and parents (P) }\end{array}$ & $\begin{array}{l}\text { Item number (V) } \\
\text { and adaptaton }\end{array}$ \\
\hline 1. Can move your wheelchair over capet? & Yes & A & $n 1$ \\
\hline 2. Can move your wheelchair around furnituse in your own home? & Yes & $\mathbf{p}$ & 12 \\
\hline 3. Can move your wheelchair over thresholds, such as between rooms? & Yes & $\mathrm{P}$ & 13 Added photo \\
\hline $\begin{array}{l}\text { 4. Can manoeuvre your wheeichair in small spaces, such as } \\
\text { a bathroom? }\end{array}$ & Yes & A,P & M \\
\hline 5. Can move your wheelchair through a door that opens automatically? & $\mathrm{No}$ & - & Deleted, less nelevant \\
\hline $\begin{array}{l}\text { 6. Can open, go through and then dose a standard } 81 \mathrm{~cm}\left(32^{\prime \prime}\right) \text { light- } \\
\text { weight doof? }\end{array}$ & Yes & - & 15 Added photo \\
\hline $\begin{array}{l}\text { 7. Can open and go through a spring loaded door, such as a door at } \\
\text { your local mall? }\end{array}$ & No & - & Deleted, less nelevant \\
\hline $\begin{array}{l}\text { 8. Can move your wheelchair up a standard ramp, built to code } \\
\left(5^{\circ} \text { incline)? }\right.\end{array}$ & Yes & CAP & 16 Added photo \\
\hline $\begin{array}{l}\text { 9. Can move your wheekchair down a standard ramp, built to code } \\
\left(5^{\circ} \text { incline)? }\right.\end{array}$ & Yes & CAP & 17 Added photo \\
\hline 10. Can move your wheekchair up a dry steep slope ( $>5^{\circ}$ incline)? & Yes & C,AP & V8 Added photo \\
\hline 11. Can move your wheelchair down a dy steep slope ( $>5^{\circ}$ incline)? & Yes & CAP & 19 Added photo \\
\hline $\begin{array}{l}\text { 12. Can move your wheelchair down a diy steep slope (>5 incline) } \\
\text { and stop as soon as you ane off the slope? }\end{array}$ & Yes & A & 110 Added photo \\
\hline 13. Can move your wheekchair up a curb cut? & Yes & $C, P$ & 611 Added photo \\
\hline 14. Can move your wheekchair down a curb cut? & Yes & $C, p$ & 012 Added phot \\
\hline $\begin{array}{l}\text { 15. Can move your wheekchair over a drainage grate and then up a } \\
\text { curb cut? }\end{array}$ & Yes & $\mathrm{p}$ & 113 Added phot \\
\hline $\begin{array}{l}\text { 16. Can move your wheekchair down a curb cut then over a drain- } \\
\text { age gate? }\end{array}$ & Yes & P & 114 Added photo \\
\hline 17. Can move your wheekchair through a pudde then up a arb at? & No & - & Deleted, less nelevant \\
\hline 18. Can move your wheekchair down a curb cut then through a pudde? & No & - & Deleted, less selevant \\
\hline 19. Can move your wheekchair through slush then up a curb cut? & No & - & $\begin{array}{l}\text { Deleted, less selevant Dutch weather } \\
\text { conditions }\end{array}$ \\
\hline 20. Can move your wheelchair down a curb cut then tirough slush? & No & - & $\begin{array}{l}\text { Deleted, less selevant Dutch wea ther } \\
\text { conditions }\end{array}$ \\
\hline $\begin{array}{l}\text { 21. Can move your wheelchair down a curb cut then though } 5 \mathrm{~cm} \\
\left(2^{2}\right) \text { snow? }\end{array}$ & No & - & $\begin{array}{l}\text { Deleted, less nelevant Dutch wea ther } \\
\text { conditions }\end{array}$ \\
\hline $\begin{array}{l}\text { 22. Can move your wheelchair through } 5 \mathrm{~cm}\left(2^{\circ}\right) \text { snow then up a } \\
\text { curb cut? }\end{array}$ & No & - & $\begin{array}{l}\text { Deleted, less selevant Dutch weather } \\
\text { conditions }\end{array}$ \\
\hline $\begin{array}{l}\text { 23. Can move your wheelchair up a standard height arb } 15 \mathrm{~cm}\left(6^{\circ}\right) \\
\text { without a curb cut? }\end{array}$ & Yes & C,A.P & $\begin{array}{l}\text { V15 Added photo + remove words } \\
\text { "without a curb cut" }\end{array}$ \\
\hline $\begin{array}{l}\text { 24. Can move your wheekchair down a standard height cub } 15 \mathrm{~cm}\left(6^{\prime \prime}\right) \\
\text { without a curb cut? }\end{array}$ & Yes & C,AP & $\begin{array}{l}116 \text { Added photo + remove words } \\
\text { without a curb cut" }\end{array}$ \\
\hline $\begin{array}{l}\text { 25. Can manceuvre your wheeldhair to press the crosswalk button and } \\
\text { cooss the street before the traffic light changes? }\end{array}$ & Yes & p & $\begin{array}{l}\text { V17 Added photo }+ \text { include words } \\
\text { "changes to red" }\end{array}$ \\
\hline $\begin{array}{l}\text { 26. Can cross a street with light traffic at a coosswalk with no traf- } \\
\text { fic lights? }\end{array}$ & Yes & p & 18 \\
\hline $\begin{array}{l}\text { 27. Can move your wheelchair across } 3 \mathrm{~m} \text { (10 ft) of flat, freshly mowed, } \\
\text { dy grass? }\end{array}$ & Yes & $C, p$ & $\begin{array}{l}19 \text { Remove words "flat, freshly } \\
\text { mowed, dry" }\end{array}$ \\
\hline $\begin{array}{l}\text { 28. Can move your wheekchair through a pothole that is wider than } \\
\text { your wheekchair and } 5 \mathrm{~cm}\left(2^{\circ}\right) \text { deep? }\end{array}$ & Yes & c & 120 \\
\hline $\begin{array}{l}\text { 29. Can move your wheelchair along a paved sidewalk that is cracked } \\
\text { and uneven? }\end{array}$ & Yes & - & 121 Added phot \\
\hline $\begin{array}{l}\text { 30. Can move your wheelchair along a flat dirt path or trail with some } \\
\text { tree roots and rocks? }\end{array}$ & Yes & $\mathrm{p}$ & 122 \\
\hline $\begin{array}{l}\text { 31. Can move your wheelchair acoss } 3 \mathrm{~m} \text { (10 ft) of flat, } \\
\text { unpacked gravel? }\end{array}$ & Yes & A & $\begin{array}{l}123 \text { Added photo + remove words } \\
\text { "flat, unpacked" }\end{array}$ \\
\hline $\begin{array}{l}32 . \text { Can move your wheekchair a long a sidewalk with } 5 \mathrm{~cm}\left(Z^{*}\right) \\
\text { of snow? }\end{array}$ & No & - & $\begin{array}{l}\text { Deleted, less selevant Dutch weather } \\
\text { conditions }\end{array}$ \\
\hline $\begin{array}{l}\text { 33. Can move your wheelchair through a cowd of people without hit- } \\
\text { ting anyone? }\end{array}$ & Yes & $\mathbf{p}$ & 124 \\
\hline $\begin{array}{l}\text { 42. Can move your wheekchair down a stose aisle that has just enough } \\
\text { room for your wheekchair without knodking items over? }\end{array}$ & No & - & Deleted, less selevant \\
\hline \multicolumn{4}{|l|}{ New } \\
\hline $\begin{array}{l}\text { Can cross a busy street, without a crosswalk or traffic light, with } \\
\text { your wheekchair? }\end{array}$ & & p & 125 \\
\hline Can cross over a road with a $5^{\circ}$ incline with your wheelchair? & & $\mathrm{p}$ & 126 \\
\hline Can move your wheeldhair up an escalator? & & $C, p$ & 127 \\
\hline Can move your whee ldhair down an escalator? & & c.p & 128 \\
\hline Can move your wheeldhaif down 3 steps without a handrail? & & CA.P & 129 \\
\hline Can move you wheelchair without anti-tipping wheels? & & C.p & 130 \\
\hline Can balance your wheelchair on the rear wheels (wheelie)? & & C,AP & 131 \\
\hline
\end{tabular}

